\title{
PADRE-CMV Fusion Peptide Vaccine
}

National Cancer Institute

\section{Source}

National Cancer Institute. PADRE-CMV Fusion Peptide Vaccine. NCI Thesaurus. Code C78820

A peptide-based vaccine containing a pan HLA DR-binding epitope (PADRE) fused to a cytomeg alovirus (CMV) peptide epitope, with potential anti-viral and immunomodulating activities. Upon administration, PADRE-CMV fusion peptide may stimulate a cytotoxic Tlymphocyte (CTL) response against CMV in the CMV-infected host. The synthetic peptide PADRE is a universal helper T cell epitope. 